\title{
Re-Envisioning ESL for Short-Term Programs
}

Marcellino Berardo, Baiba Šedriks, Geri Lamer, and Marina Greene University of Kansas

Keywords: ESL professional, short-term programs (STPs), English for academic presentations (EAP), international education, Education Program Coordinator

\begin{abstract}
ESL professionals have traditionally taught the four language skills, vocabulary, and grammar in Intensive English Programs (IEPs) to help incoming students satisfy the university's ESL requirement. As international education continues to change, however, the ESL profession will need to re-conceptualize its role and make explicit its evolving relevance. IEPs and traditional ESL classes are not necessarily applicable to short-term programs, whose purpose is to give participants some experience at a US institution with a focus on a specific discipline or area of study. This paper demonstrates two ways ESL professionals reenvisioned their role at the university for short-term programs (STPs) by creating English courses for the international education experience. With linguistic and cultural guidance from the ESL instructors, participants in these English courses critically analyzed impactful observations, perceptions, ideas, or events from the STP and gave PowerPoint presentations at a program-wide conference on their analysis of one academic or non-academic concept or observation that had the most impact.
\end{abstract}

\section{Introduction}

American universities are forming partnerships with universities around the world and some of these partnerships include opportunities for international students, scholars, and teachers to come to the US for a short period of time to study, receive professional training, and do research. At the University of Kansas, a short-term program is defined as an international program of non-degree seeking participants (traditional students, professionals and scholars) who are at the university for less than a year (e.g., three weeks to nine months). Programs are developed for each group to meet the goals expressed by the program's sponsor. Participants are admitted and enrolled in university classes, which makes them eligible to live in campus housing and enjoy all the rights and privileges of students at the university.

\section{Short-term Programs and Traditional ESL}

Sponsors of short-term programs may choose to exclude an English language component for various reasons. For example, the traditional ESL courses on the four language skills (reading, writing, speaking, listening comprehension), grammar, and vocabulary may seem unnecessary because program participants may have higher English language proficiency levels than the Intensive English Program (IEP) offers. Furthermore, traditional ESL classes in the IEP 
may seem irrelevant because the program might be designed to give discipline-specific experiences for students in the sciences, professional schools, or disciplines other than English.

The very purpose of traditional ESL classes may be irrelevant to the STP. Traditional ESL classes in the IEP are intended to help incoming students fulfill the University's ESL requirement in order to facilitate the transition into General Education courses or the chosen academic program, which is not the purpose of STPs. Program participants attend the University for brief, intense exposure to a unique academic experience put together by the program sponsor in conjunction with University administrators and Schools and departments at the University. Participants leave the university once the program ends.

Finally, the short-term program may not be a good fit for IEP classes due to scheduling. STPs of varying lengths cannot follow the university's semester schedule, which could disrupt the IEP class community when class numbers suddenly increase as STP students arrive and decrease as the program concludes and participants leave.

\section{Re-envisioning ESL for the Short-term Program}

Although traditional ESL classes and the University IEP may not be a good fit for the short-term program, this, however, does not make the ESL professional irrelevant to short-term programs. The ESL professional can and should play a central role in the short-term international education experience even when the purpose of the program is not to work on English language skills. ESL, or more specifically English for academic purposes, is re-envisioned for STPs as a means for providing the linguistic resources and relevant information about the academic institution, local culture and environment, and adjustment process to help participants interpret and critically reflect on their international experience. In this sense, the ESL classroom becomes the space for participants to articulate new feelings, opinions and thoughts, and receive feedback in order to integrate the international experience into the participants' existing understanding of "how the world works."

The international experience itself adds value to the education that participants receive in STPs. Reconciling unfamiliar experiences with one's understanding of how the world works constitutes important change in the individual and therefore should be an explicit and core goal to any international education program, including short-term programs. Moreover, this change is facilitated by a language component designed to incorporate aspects of the STP from both inside and outside the classroom. In this model, language is the key vehicle used to address reactions to and interpretations of the international experience. This central role of the second (or additional) language requires the expertise of the ESL professional. Elaborating on the importance of language in the international experience, Althen (2011) considered language and reflection as key to learning about the new culture, which can be done by asking questions, practicing the local variety of the language, keeping a journal, reading and reflecting (pp. 249260).

This kind of English language classroom also addresses an important critique in the study abroad literature, namely that simply enjoying a short-term study abroad experience is not academically sufficient. Citing various studies, Landon, Tarrant, Rubin, and Stoner (2017) stated 
that "[i]nstitutions of higher education have been challenged to move beyond measuring the success of study abroad in terms of student enrollment and satisfaction and to foster higher-order learning outcomes (e.g., values, attitudes, beliefs, knowledge, and behaviors)" (p. 1). As part of a STP, the kind of ESL discussed here fosters higher-order learning outcomes by helping participants critically examine their experiences.

\section{English for International Education}

ESL is re-envisioned for STPs as English for the international education experienced or abbreviated simply to EIE. The international education experience is broadly characterized here by "psychological reactions to unfamiliar environments" (Furnham \& Bochner, 1986; Ward, Bochner, \& Furnham, 2001) that STP participants have. Such reactions extend to any number of new "environments" including the new geography, plants and animals, hygiene, medicine and medical practices, transportation, food and drink, entertainment, social mores, as well as the invisible institutional structures and values of the university. EIE promotes critical reflection and interpretation of reactions and experiences through English. This idea, in fact, is not new. For example, Dressler and Tweedie (2016) examined journaling in short-term study abroad programs because of its role in helping international students articulate topics of interest, "express their feelings, draw upon their learning outside of class (field trips, homestay, etc.), and bring their intercultural learning into the dialogue" with an instructor (p. 940).

An English language component in an EIE course can still be useful even in STPs with participants who are proficient in English. For example, Niranji, Pathirage, Walpitage, and Skolits (2014) report on the benefits of an ESL class for degree-seeking international students who have already fulfilled their university's ESL requirement. They concluded that “...the ESL course was helpful with [the students'] college classes, for their adaptation to American culture, and in creating a broader social network with peer students and the larger community in which they study" (p. 32). This is the spirit of English for the international education experience, where students are advanced speakers and do not need to fulfill the university's ESL requirement to take General Education classes or classes in an academic program. The focus of EIE, then, can be on culture, networking, and the community as well as academics and other new "environments" the students encounter.

\section{Short-Term Programs and the Education Program Coordinator}

There are a number of non-academic aspects of short-term programs that affect the participants. Here we briefly characterize the role of the Education Program Coordinator in an STP to reveal some relevant non-academic aspects. The Education Program Coordinator and other STP staff members address the most important among non-academic aspects, basic human needs of the participants. An older but still useful categorization of basic human needs is found in Maslow (1954, pp. 80-92). ${ }^{1}$ Maslow's hierarchy of basic human needs specifies five categories: (a) physiological, (b) safety, (c) belongingness and love, (d) esteem, and (e) the need for self-actualization. ${ }^{1}$

\footnotetext{
${ }^{1}$ Other examples of the continuing relevance of Maslow's hierarchy can be found in publications on health care such as Lester (2013) and Karnatovskaia, Gajic, \& Bienvenu (2015).
} 


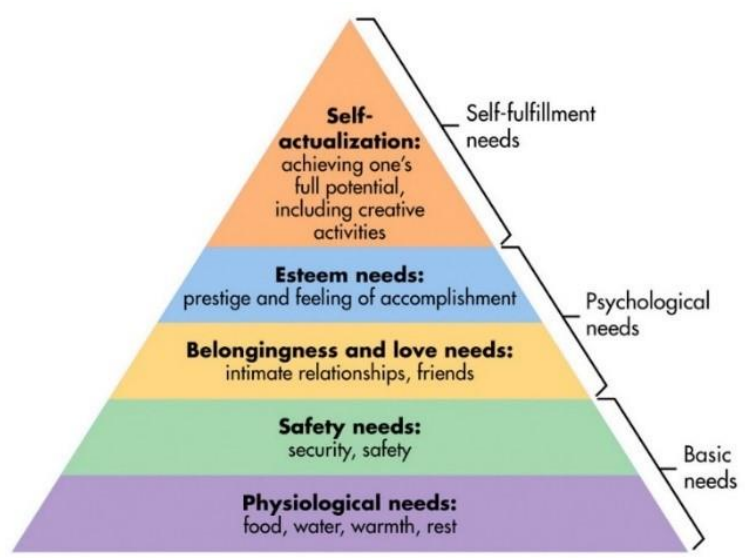

Figure 1. Maslow's Hierarchy of Needs as a Model for the Education Program Coordinator ${ }^{2}$

The Education Program Coordinator and team address the basic needs of the participants starting at arrival by helping participants get safely to campus and providing assistance with housing needs, and information about the dining hall, health and safety on campus, internet access, and economy shopping for necessities. The STP team also gives campus and downtown tours, explains the city bus system, provides opportunities to meet with both domestic and international students, accompanies participants on local and out-of-town cultural field trips, and helps participants prepare for their trip back to their home country. In short, the STP team provides continuous information and support to all participants from arrival to departure.

It is important to note that STP participants can and do have significant reactions to these experiences, which include opinions on how those needs are met or whether they are met. The Education Program Coordinator can mediate perceptions, but the ESL professional can encourage participants to arrive at a deeper understanding of opinions and reactions.

The relationship between the Education Program Coordinator and the ESL professional can be represented in Figure 2, where the Education Program Coordinator and team, represented by Maslow's Hierarchy from Figure 1, address (basic) needs of short-term program participants while the ESL practitioner, represented by Bloom's Taxonomy (critical thinking strategies), adds value by leading participants to critically examine reactions and perceptions, contributing a layer of depth to the international education experience.

\footnotetext{
${ }^{2}$ See (https://www.simplypsychology.org/maslow.html) for more information.
} 


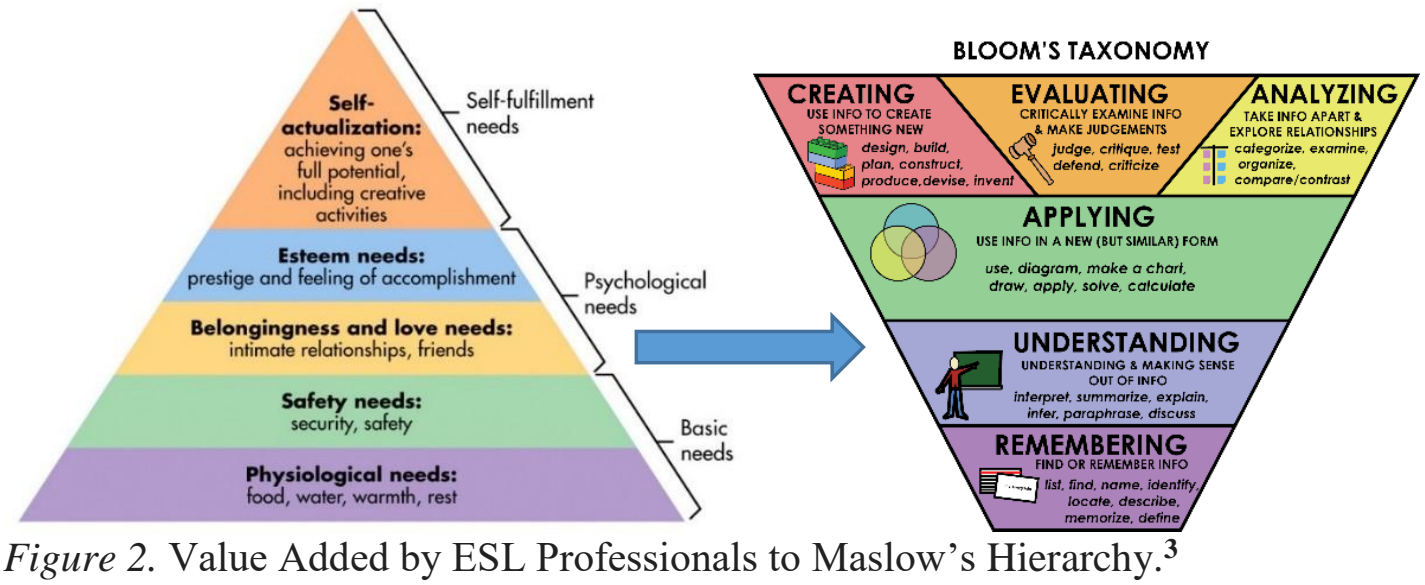

\section{Two Short-Term Programs}

The two programs discussed below are with Capital University of Economics and Business and Central China Normal University. The participants in the two programs have been selected because of their advanced stage in their academic career, their familiarity with academic English and their discipline. Each program culminated in an international conference, where participants were the presenters. The theme of the conference was a critical analysis of an impactful event or insight from the international education experience. The experience may or may not be academic; what matters is that the participant felt significantly impacted by the experience.

Figure 3 represents a larger view of how ESL professionals added value to the two STPs by helping participants modify their initial observations, reactions, and assumptions concerning any aspect of the international education experience. Acting as cultural and academic consultants as well as language instructors, ESL professionals worked with program participants to critically examine the international experience (e.g., Bloom's Taxonomy, Hall's Iceberg Analogy of Culture) through language (e.g., pronunciation and grammar) and from an academic English perspective, which included summarizing research and giving presentations.

\footnotetext{
${ }^{3}$ Source for Bloom's updated Taxonomy: https://kpu.pressbooks.pub/learningtolearnonline/blooms-graphic/
} 


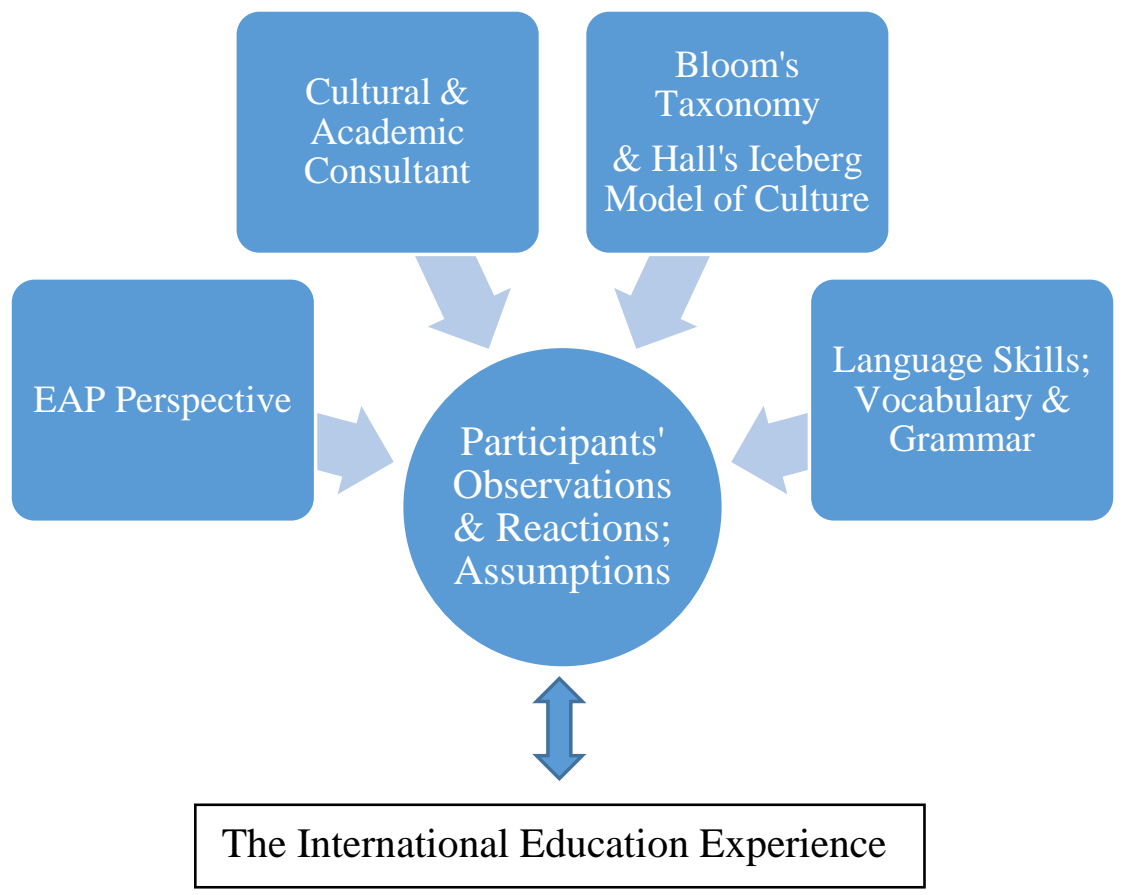

Figure 3. Four Ways ESL Professionals Add Value to STP Participants' Observations, Reactions, and Assumptions.

The rest of the paper offers a brief description of the EIE components of two short-term programs, which differ in their length of stay and disciplinary focus.

\section{Capital University of Economics and Business (CUEB)}

CUEB is in Beijing, China. Participants in CUEB come to the University of Kansas for four weeks to study economics, business, and/or public affairs. The short-term program in summer 2018 was geared toward public policy and included a total of 17 participants comprising of undergraduate and graduate students. The academic program centered on lectures (in English) by faculty in the School of Public Affairs and Administration and meetings with graduate student mentors. Also part of the program were a mandatory health center checkin, tours of campus, shopping excursions, dorm life and dorm food, attendance at sporting events, trips to surrounding cities (Kansas City, Missouri and Topeka, Kansas), and a cookout at a local lake.

\section{English for international education - CUEB.}

We divided the EIE course into two parts: (a) academic culture and research skills and (b) the international experience beyond the classroom. Our job was to help the students understand what it means to participate in an international education program. Our question was, "how can the ESL professional help CUEB participants critically examine and express impactful experiences from the international experience?" Our task was to facilitate critical reflection and 
interpretation of experiences in a program that is geared toward Public Policy and has both graduate and undergraduate students at various advanced levels of English proficiency. A brief description of the EIE curriculum in the CUEB program is given below to illustrate how we answered our question and addressed our task.

\section{Part A: Academic culture and research skills.}

The organization of the American university. We began the semester with a general introduction to how the US University is organized into Schools and Colleges and further into departments. We included academic titles (e.g., assistant, associate, and full professor) and roles (teaching, research) as well as administrative titles (e.g., Dean, Provost, and Chancellor) and roles (e.g., raising funds, oversight of instruction and research) and used the university webpages as materials. This discussion included orientation to the organization of the university and allowed for the CUEB participants to identify similarities and differences between their university and the University of Kansas toward exploring (dis)advantages of each school.

Finding Research in Library Databases: In this section of the program, we brought the participants to one of the library's computer labs to introduce them to the available databases. After a general orientation to the databases, students researched topics of interest, which may or may not have included topics in the lectures they were attending. Important here was the orientation to library databases that participants returned to throughout the program.

Summarizing and evaluating research. After researching topics, participants had the opportunity to practice summarizing and evaluating the research. For this part of the program, the instructors used summary/evaluation activities inspired by Swales and Feak (2012). Summarizing activities included multiple readings of a text, listing key points and some support, and reflecting on the strength of the claims made in the article (Swales \& Feak, 2012, pp. 189-190). Evaluation activities included considering the audience and the purpose of the material, relevance of the claims or hypotheses, and critical examination of the evidence, conclusions, and assumptions (Swales \& Feak, 2012, pp. 249-250).

Pronunciation and Grammar Practice. Participants also had the opportunity to give inclass oral reports on their formal research or any other impactful experience. At this point phrasal stress, intonation, and the pronunciation of vowels were reviewed and practiced. Also practiced were key grammar structures associated with reporting verbs such as noun clauses. The specific reporting verbs were chosen from the field of marketing: "suggest, argue, demonstrate, propose," and "show" (Hyland, 1999, p. 349). Examples of formulaic phrases for reviewing literature and referencing include, the main claim in this paper, the authors provide evidence for, and Smith (2019) adds to the literature with. For more examples, see Feak and Swales (2009).

PowerPoint Presentations. We found that CUEB participants had much experience with PowerPoint technology but still needed feedback on organization and the use of bullet points to summarize ideas using parallel grammar structures. Also, included in this part of the course was a review of citations, PowerPoint design with visuals, and appropriate uses of animation. Of course, there was also ample opportunity for participants to practice explaining their ideas using PowerPoint slides. This component was key to the EIE course and CUEB program because 
students needed to use a PowerPoint presentation to report on their insights into an international education experience at a program-culminating conference.

\section{Part B: International Experience beyond the Classroom.}

An international educational experience goes far beyond the classroom. Toward the end of the program, we wanted to help the participants identify and examine any aspect of their international experience that had a significant impact.

Iceberg Concept of Culture. To provide a way to think about their experiences in some depth, we introduced Hall's (1976) familiar Iceberg analogy of culture to demonstrate the idea of overt, easily seen aspects of culture (e.g., food, behavior, language) and covert or "unseen" aspects of culture such as values, beliefs, attitudes, and underlying assumptions. We wanted the participants to attempt some analysis or explanation for their observations and reactions, not to arrive at the answer but to guide the participants in thinking more deeply about their international experience.

Journaling. From the outset of the course, we introduced journaling to encourage critical reflection on experiences and reactions and to enter into a dialogue with the instructor. Each student received a Blue Book, which is a stapled blue-colored booklet consisting of lined paper traditionally used at universities for essay exams. Participants were encouraged to document and explore observations, reactions, sounds, smells, tastes, behaviors, surprises, and any insights, reflections, or frustrations.

The participants turned in their journals periodically and received two kinds of feedback: linguistic and critical guidance. Linguistic feedback included grammar, word use/choice, collocations, and formulaic expressions. Critical guidance included cultural information, questions, and suggestions to help the participants get more information and think more deeply about their experience. For example, one participant was baffled at why US students did not use umbrellas on hot, sunny days. She explained that even with an umbrella she was getting a tan, a sign of ugliness. She had anxiety about how her family would respond when they saw her tan. She was encouraged to investigate attitudes toward the sun and beauty. She also received feedback to help approach students in her dorm about this issue in order to understand this seemingly irrational American attitude about tans and choosing not to use an umbrella on hot, sunny days.

Debriefing Sessions. In addition to journaling observations and reflections, time was allotted for debriefing sessions, where participants brought in their Blue Books and discussed with the class what was impacting them. These sessions provided participants with an opportunity to convert their international education experiences into speech by practicing turntaking and conversation skills. A typical session allowed for each participant to introduce one issue and for others to comment. Comments were often shared such as the universal curiosity about the American practice of drinking ice water and the appearance of cheese in seemingly almost every dish. 


\section{KU-CUEB: Conference on International Education.}

The CUEB program concluded with a conference, where each participant created a brief PowerPoint presentation to highlight one academic or non-academic aspect of the international education experience that had the most impact. Participants prepared for and practiced their presentation in the EIE class. A representative list of conference titles is given below to offer a sample of topics that participants found noteworthy.

\section{Selected Presentation Titles.}

- Umbrellas and Cold Water: Strange Customs or Something Else?

- My Discoveries of American Teaching Style

- Three Interesting Observations of America: Guns, American Dream, and the Capitol City

- Some International Experiences and My Takeaways from the Program

- Differences between Chinese and American Sports Culture

- The Culture of Sneakerheads

\section{Central China Normal University (CCNU)}

CCNU is located in Wuhan, China. This eight-week program was for juniors and seniors majoring in education. The academic program centered on lectures by faculty in the School of Education. Participants also took a core course in the School of Education, Universal Design for Learning, and attended lectures on current practices in teaching mathematics, science, the humanities, and language. In addition, participants observed classes in local primary and secondary schools as well as courses at the University. Outside of the classroom, participants went to a pep rally, college football game, basketball game, and homecoming parade. They also traveled to the state capitol to see the capitol building and the Kansas History Museum. Several optional activities were also available such as the community arts and music festival, the Halloween community outreach event, and the Mid-Autumn Festival moon viewing party.

\section{English for international education - CCNU.}

Our job, again, was to help the students understand what it means to participate in an international education program. Our question for this program was, "how can the ESL professional facilitate critical reflection and interpretation of impactful experiences in this shortterm international program that is geared toward education majors interested in advances in US teaching practices?" Similar to the CUEB program, CCNU students were required to journal their experiences in Blue Books. Unlike the EIE course in the CUEB program, the EIE course in CCNU included an English for academic purposes component (EAP) for education majors.

The organization of the School of Education. Unlike discussion on the general organization of the American university in the CUEB program, focal points in CCNU were the organization of the School of Education as one School at the University with five departments, namely the Departments of Curriculum and Teaching, Educational Leadership and Policy Studies, Educational Psychology, Health, Sport, and Exercise Sciences, and Special Education. The College of Liberal Arts and Sciences houses content departments such as 
history, physics, psychology, and mathematics. This part of the course also reviewed the University's General Education requirements and what the University considers as a wellrounded education. The point of this discussion was to explore what education means in the US and identify (dis)advantages of how teachers are educated in the US by contrasting with CCNU.

Overarching goals. The EAP course was organized around the four goals of EAP developed at the University of Kansas: Access, Understand, Re-create, and Critically question/discuss disciplinary content or AURC (Berardo \& Smith Herrod, 2015; Sood $\&$ Taveggia, this volume). Students used the pedagogical design of the etext to $A U R C$ selected chapters. This kind of EAP component of CCNU was not present in the CUEB program because CUEB was shorter in length and materials were not as available.

EAP for education majors. Another difference between CUEB and CCNU was that all CCNU participants took a course in the School of Education called, Universal Design for Learning. The e-textbook for the education course was also used in the English course, but our EAP focus was on education discourse as represented in the e-textbook. The discourse took the form of definitions of key terms, extended explanations and examples, applications, and summaries. Unfamiliar and discipline-specific vocabulary, phrases, and collocations were highlighted. Also examined in the EAP component were short videos of K-12 teachers talking about their classes. This was made possible because the e-textbook had short embedded videos of the teachers.

Oral discourse. Additionally, the CCNU participants were exposed to a variety of spoken academic registers in the EAP classroom. Analysis of the UDL embedded videos and educational-minded TED Talks afforded the participants the opportunity to evaluate academic language through the lens of a variety of presentation approaches. Moreover, participants were tasked with creating their own digital stories based on a particular audience. Practice in the digital humanities through the use of Pecha Kucha, a presentation format which relies on visuals, was contrasted with "live" in-class mini-talks. This in turn allowed participants to critique language (e.g. word choice, transitions, discourse markers, non-verbal communication) as well as body gestures (e.g. facial expressions, eye contact, hand movements) in diverse academic approaches.

Journaling. As in CUEB, participants in CCNU journaled their opinions and reactions to what they were experiencing in the classroom and outside the classroom. Some "classroom" or academic topics that participants wrote about were new, intellectually interesting ideas and discussions with graduate student mentors in the School of Education. Participants were also asked to journal about their visits to local K-12 schools and university classes as well as campus life (dorm life, library, transportation, recreation, and college sports), the city of Lawrence, Kansas, interactions with American students, perceived American attitudes and motivations of behavior, the food, weather and cultural adjustment issues. For example, some participants found it odd that domestic students washed their clothes in washing machines and used driers rather than simply doing their laundry by hand at the end of the day. This observation and perception opened an avenue for learning about social practices. 
KU-CCNU: Conference on international education. Unlike the participants in the CUEB program, CCNU participants chose more academic topics to present at the conference. This sampling of presentation titles reveals the range of topics that made an impact on the CCNU students.

Selected Presentation Titles.

- A Comparison of Chinese and American High School Chemistry Textbooks

- Adjusting Universal Design for Learning to the Physics Classroom in China

- A Comparison of Chinese and American High School Music Curricula

- Nice to Meet Hip Hop

- My Ideal Math Curriculum: Taking the Best from Chinese and American Pedagogy

- My English Language Experience: A Key to a New World

\section{Conclusion}

Short-term programs provide participants with a brief opportunity to study, research, or simply experience how a discipline is taught or a profession is practiced overseas. The more proficient the participants are in English, the more they can benefit from the program. In fact, participants in the two programs discussed in this paper were chosen because of their advanced English proficiency as well as their advanced level in their studies. On the surface, it might appear that ESL professionals would not be relevant to these kinds of short-term programs, but as international education experts, ESL professionals can re-envision their role and enrich the international experience by providing (a) cultural and academic information about the US and institution, (b) critical guidance to help participants reach deeper insights into the educational experience, (c) linguistic tools to articulate evolving understandings, and (d) an EAP perspective. The conference presentation, as a culminating event, facilitated critical reflection on the international education experience. 


\section{References}

Althen, G. and Bennett, J. (2011). American ways: A cultural guide to the United States. Boston: Intercultural Press.

Berardo, M. and Smith Herrod, K. (2015). Teaching English for Academic Purposes in the KU Academic Accelerator Program. Issues in Language Instruction, 4(1), 20-24. DOI: https://doi.org/10.17161/ili.v4i1.7008

Dressler, R. and Tweedie, M. (2016) Dialogue journals in short-term study abroad: "Today I wrote my mind." TESOL Journal, 7 (4), 939-967.

Hall, E. T. (1976). Beyond Culture. New York: Doubleday.

Hyland, K. (1999). Academic attribution: Citation and the construction of disciplinary knowledge. Applied Linguistics 20 (3), 341-367.

Feak, C. and Swales, J. (2009). Telling a research story: Writing a literature review. Ann Arbor: University of Michigan Press.

Furnham, A. and Bochner, S. (1986). Culture shock: Psychological reactions to unfamiliar environments. London: Methuen.

Karnatovskaia, L., Gajic, O., and Bienvenu, O. (2015). A holistic approach to the critically ill and Maslow's hierarchy. Journal of Critical Care, 30, 210-211.

Landon, A., Tarrant, M., Rubin, D., and Stoner, L. (2017). Beyond “just do it": Fostering higherorder learning outcomes in short-term study abroad. American Educational Research Association (AERA) Open, 3(1), pp. 1-7. https://doi.org/10.1177/2332858416686046.

Lester, D. (2013). Measuring Maslow's hierarchy of needs. Psychological Reports: Mental \& Physical Health, 113(1), 15-17.

Maslow, A. (1954). Motivation and Personality. New York: Harper \& Row.

Niranji, D., Pathirage, J., Walpitage, D., and Skolits, G. (2014). Helpfulness of ESL courses for international students studying in the United States. International Education, 43 (2), 2538.

Sood, P. and Taveggia, D. (2019). From general ESL to EAP: A fall leap. Issues in Language Instruction 8, present volume.

Swales, J. and Feak, C. (2012). Academic writing for graduate students: Essential tasks and skills. Ann Arbor: The University of Michigan Press.

Ward, C., Bochner, S., and Furnham. (2001). The psychology of culture shock. Philadelphia: Routledge. 